\title{
Chapter 5 \\ Reimagine Elementary and Secondary \\ Learning During the Pandemic: Tsinghua University
}

\author{
Deyu Woody Wang, Weihang Cheng, Yun Jin, and Manwen Ivy Guo
}

\begin{abstract}
New technologies inspire the reforms in education. A global pandemic that kept people including students and teachers in their homes only accelerated the progress of adopting new ways for students to learn and for teachers to teach. This chapter presents two programs carried out by Tsinghua University and Tsinghua University High School to provide adequate learning experience for students even when they cannot attend school physically. The merits of the two programs are not only reflected in the new content students learned, but also emphasized by the fact that students from distant areas and diverse backgrounds can form online learning communities that continue to exist after the pandemic. Finally, how teachers inspired undergraduates to act as peer learners for younger students is also inspected and discussed here.
\end{abstract}

\subsection{Introduction}

Tsinghua University is one of the most prestigious and influential universities in China. Established in 1911 and now a public university located in Beijing, Tsinghua has 20 schools and 59 departments with 3600 faculties members in science, engineering, humanities, law, medicine, history, philosophy, economics, management, education, and art. Tsinghua University has 50,000 registered students, including 16,000 undergraduates, 18,000 post-graduates, and 16,000 doctoral candidates. Within its main campus in Beijing, Tsinghua University also hosts a network of schools, including Tsinghua University High School (THUHS),

\footnotetext{
D. W. Wang $(\bowtie)$

iCenter, Tsinghua University, Beijing, China

e-mail: wdy@tsinghua.edu.cn

W. Cheng $\cdot$ Y. Jin

Tsinghua University High School, Beijing, China

M. I. Guo

Chieon Future Ed Tech, Beijing, China

(C) The Author(s) 2022

F. M. Reimers, F. J. Marmolejo (eds.), University and School Collaborations

during a Pandemic, Knowledge Studies in Higher Education 8,

https://doi.org/10.1007/978-3-030-82159-3_5
} 
Tsinghua International School, Tsinghua University Primary School, and Jiehua Kindergarten, covering all pre-K to Grade 12 for both national curriculum and AP courses.

Tsinghua graduates follow diverse career paths in academia, industry, and government. Among them are award-winning members of academies, professors of world-class universities, government officials, as well as founders of overseas listed companies and leaders of multinational companies. Tsinghua alumni are also active worldwide in many countries, and around 20,000 alumni currently stay abroad, mostly in North America. There are nearly 50 Tsinghua alumni organizations in over ten countries.

The following excerpts from the president's address provide a glance at the strategic plan of the university:

Tsinghua continues embracing the world with open arms and confidence. The vision of the university shapes the kindred minds of its talents. Tsinghua continues to pursue innovation and creativity. In the past year, Tsinghua celebrated a range of ground-breaking achievements in areas of AI, physics, electronics, bioscience, archeological discoveries, and literature. As for the overall academic planning and strategy, Tsinghua continues to promote the development of humanities, engineering, and science disciplines through a series of comprehensive implementation plans. Innovation is the best course of action at a new age that presents us with unprecedented opportunities and challenges. ${ }^{1}$

The onset of the COVID-19 pandemic brought challenges to the university itself. The president's office assembled a fast response team to coordinate academic affairs during this period. All students were required to stay put instead of coming back to campus. Faculties prepared and delivered all spring semester courses through Rain Classroom, a native online learning platform developed by Tsinghua Online Education Office in 2016, and other online meeting software such as Tencent Meeting and Zoom. Meanwhile, XuetangX, the MOOC platform launched by Tsinghua in 2013, hosted over 2300 courses provided by universities globally, among which Tsinghua offered over 1900 free of charge to the public.

Tsinghua University High School (THUHS) adopted a strategy of blended learning well before the pandemic. In 2016, THUHS began to build its own online learning platform, and by 2020 , it had already offered thousands of students and faculties with modularized learning tools. Given that the transition toward online learning was rather smooth for THUHS, the focus was on accelerating the progress of restructuring curriculum and learning experience.

Among all these efforts, several Tsinghua University subsidiaries initiated programs to support elementary and secondary education. The goal of such efforts is to fulfill social responsibilities and to find new possibilities in online learning. This chapter aims to examine the approaches taken by different parties in various scenarios of elementary and secondary education engagement.

\footnotetext{
${ }^{1}$ Revised from "Message from the President-Tsinghua University" https://www.tsinghua.edu.cn/ en/About/Message_from_the_President.htm. Retrieved 9 July, 2020.
} 


\subsection{Connecting Online, Bridging the Gap}

Alongside the efforts to maintain the quality of learning in courses, Tsinghua launched initiatives covering a broad spectrum of K-12 students, teachers, and parents. This chapter includes two cases that focus on exploring a new way of onlinecommunity-based learning that empowers K-12 learners on social, operational, and strategic levels. In case 1, Innovative Talent Cultivation Open Forum (ITCOF) hosted by K-16 Technology and Engineering Education Alliance (K-16 Alliance) invites educators, researchers, and practitioners from universities, schools, as well as governments to share insights into education for innovative talents. In case 2, the Student Development Center of THUHS hosts the Minds of Youth (MoY) learning camps that create online collaborative learning communities for students from different parts of the nation, including sixth graders up to undergraduates.

K-16 Technology and Engineering Education Alliance (K-16 Alliance) was cofounded in 2019 by Tsinghua iCenter, together with research centers of the Ministry of Education, universities, and schools. The mission of the K-16A is to build a stronger tie between K-12 and higher education, specifically in nurturing innovative talents. The Innovative Talent Cultivation Open Forum (ITCOF) has hosted 18 online public talks in 6 weeks, with speakers from Tsinghua University, Beijing Normal University, high schools, and ed-tech companies. These talks cover various topics, including education research, policy review, education outlook, learning and teaching strategies, and best practice review. The ITCOF creates an easy-to-access way to share challenges and know-how for K-16 educators. The speakers address the issues that arise during the pandemic and will continue to last into today's everchanging world. The talks are broadcasted through multiple channels to reach out to different audiences. Data from the top viewing portal shows that ITCOF was viewed over 714,000 times across the nation with over 96,000 unique viewers. Comments on the talks show that the forum bridges the gap between educators of different grades, especially between teachers from K-12 schools and universities.

A series of learning camps named Minds of Youth (MoY) were designed for THUHS students after the onset of the COVID-19 pandemic in 2020. It has created a more concentrated learning experience and a sense of bonding for K-16 students. The 5-day online learning camps aim to provide opportunities for participating students to learn how to stay positive while learning at home away from friends and teachers. As an online learning consortium, MoY also encourages students to associate with peers and other learning partners in the community, helping them maintain a high level of self-efficacy in the online learning scenario. From March to May, three MoY camps had attracted 152 middle school students from sixth to eleventh graders, 14 Tsinghua undergraduates, and 7 Tsinghua faculties. Participants reported that the camps opened up a new perspective for the pandemic and helped them embrace the abrupt change in ways of learning. The blended learning community with university students brought unique opportunities for teenagers to make friends with and learn from their senior peers, thus cultivating social and emotional competence beyond a positive self-identity. 


\subsection{Rationale and Motivation}

With the motto of "Self-Discipline and Social Commitment" and the spirit of "Facta non verba (Actions speak louder than words)", Tsinghua University strives to influence younger generations on building up a strong will and an intelligent mind. Each summer, the Tsinghua Summer Schools are open to high school students. Many other activities, such as Lab Open Day and Lab Tours, welcome thousands of students from all around the country each year. XuetangX launched 7 years ago has already proven to be a practical approach to deliver knowledge. To have a positive influence on young learners and talents is part of Tsinghua's mission. During the pandemic, Tsinghua University opened all spring courses online according to the academic calendar while maintaining high teaching and research standards. In addition to undergraduate courses, faculty members used the Internet to deliver quality content, such as parallel courses that students from partner universities in Wuhan can take and get credits from. For younger generations, Tsinghua launched programs for sixth and twelfth grade students, especially those in the epicenters, to provide more opportunities for them to have genuine experiences with Tsinghua.

Online-community-based learning is a continuation of learning innovation that emphasizes learning in the context of society. As part of the general policy to enrich middle and high school student experience from the Beijing municipal government, students are supposed to take 6-8 days of social field study across the nation or even abroad per semester. The online learning format has opened up new possibilities to reach out further to local learning communities in both urban and countryside areas. Video conference, WeChat groups and other low-cost solutions enable students and teachers to learn and work with peers remotely without compromising the quality and intensity of interactions. We argue that in the digital era, online learning communities will become permanent infrastructures for students to learn together over long distances.

Both ITCOF and MoY serve the purpose of enhancing students' career and life planning by connecting the learning experience in a college with elementary and secondary levels of learning. We argue that a stronger connection with learning communities of higher grades and deeper understandings of what to expect in the future study will help younger students perceive studying as a whole to be more purposeful and, hence, increase the engagement with learning activities.

\subsection{Case 1: ITC Open Forum}

"Innovative Talent Cultivation Open Forum" (ITCOF) is a series of online talks that bring together education practitioners from universities and K-12 schools. As part of the K-16 Alliance yearly events, ITCOF serves the purpose of enhancing communication across different stages of learning. The invited speakers include professors from Tsinghua University and Beijing Normal University, experts from 
government research institutes, and teachers from top middle schools. Over 90,000 unique viewers watched 18 talks on various topics and interacted with speakers in WeChat group chats. The approach received positive feedback from participating students, parents and teachers.

ITCOF is hosted by Tsinghua University iCenter, together with the Beijing Institute of Science Education Innovation (BISEI) and China Education Innovation Institute of Beijing Normal University (CEII). QC Maker, an education startup founded by Tsinghua graduates, runs the online event platform and coordinates the speakers. ITCOF aims to empower students, inspire teachers, and inform parents. Students of grades 7-12 can learn from professors and get first-hand information on their latest research projects. Teachers and parents can get insights into up-to-date policies released by the Ministry of Education and universities. The forum also serves to fulfill the social responsibilities of Tsinghua University by inviting young students to experience university studies before they get enrolled.

The forum is fully open and free to all audiences. Beijing Association for Science and Technology (BAST) provides funding to cover the cost of inviting speakers, recording, as well as bandwidth and platform maintenance. BAST also offers technical support for the live talk platform adapted by QC Maker for these events.

\subsubsection{Participants}

As of June 30, 2020, the organizers had invited professors, researchers, science teachers, and industry leaders as guest speakers to the forum. Eight professors and researchers were from universities or research institutes, including three from Tsinghua. Eight principals and science teachers were from high schools. Two experts were from the science education and design industries.

The organizers posted digital flyers primarily via WeChat, the most popular instant messaging app in China, and reached out to students through the network of K-16 Alliance. Over 80 schools received the invitation to the forum and spread the information among students and parents. According to data analytics of the live show platform, 96,416 unique users from 15 cities in China had registered and viewed at least one live or recorded talk as of June 30,2020. Since the forum was open and free, the organizer did not collect any specific information upon viewer registration. However, the organizers analyzed the comments left by the viewers and identified four typical audiences:

1. Students. They are undertaking specific science projects in their schools.

2. Science teachers. They are dedicated to mentoring students' science projects or giving science courses in schools.

3. Parents. Their kids are interested in or are already undertaking science projects.

4. Sales representatives/R\&D engineers. They are from science education hardware suppliers. 
Although the exact proportion of these types of audiences is unknown, it is estimated that the majority of the viewers are science teachers and parents, each accounting for $40 \%$.

\subsubsection{Method}

The forum consists of one-hour online live talks on a tri-weekly basis. The audiences can view the talks and leave comments on smartphones or computers but cannot talk directly to the speakers. Speakers will respond to selected comments after the talk. Alongside 18 talks, a special event invited the audiences to a virtual tour of Tsinghua iCenter with detailed explanations about various advanced technologies, including AI-embedded flexible manufacturing, additive manufacturing with non-metal and metal materials, and high-precision optical inspection.

Each week, three speakers gave talks individually on three consecutive nights. Speakers used slideshow screen shares to present the content while appearing live through video. Every talk lasted one hour with selected topics on science education. The diversity of speakers' backgrounds allowed the audiences to approach the issue of science education from distinct perspectives - from elementary to university levels (Table 5.1).

The organizers created a WeChat group chat for speakers and audiences each week. Audiences were encouraged to raise questions before the talk and extend the discussions into the group chats after the talk.

\subsubsection{Data and Results}

Students viewing counts and the number of audiences for each lecture are collected from the online community administration console. By June 30, 2020, the top speech had received 171,445 numbers of live views from 17,296 viewers. It was given by the former principal of Beijing No. 4 High School, which ranks among the top 10 schools in Beijing and sends hundreds of students to prestigious universities in China and abroad each year. A lecture given by Jian Liu, Head of China Education Innovation Institute, received 156,735 live views from 10,639 audiences, ranking second on the list. Some other top speakers include experts in innovation project mentoring, professors from Tsinghua University iCenter, and experts in psychology and computer sciences. Though a limited number of feedbacks are collected

Table 5.1 Numbers of ITCOF talks hosted by speakers from different backgrounds on different topics

\begin{tabular}{l|l|l|l}
\hline & University/research institute & Schools & Industry \\
\hline Strategy & 6 & 4 & 0 \\
\hline Practice & 2 & 4 & 2 \\
\hline
\end{tabular}


afterward, the viewing numbers demonstrate the popularity and impact of ITCOF. Today, recordings of all talks are still being reviewed by more people who are interested in related topics.

\subsubsection{Next Steps}

A more formalized assessment system would be in place for future events in this series. Key parameters about the lectures will be collected on the online platform to yield more meaningful information about the audience and their gains from attending the event virtually.

We also plan to conduct a survey among high school teachers and parents on their feedback about previous events and expectations for future events.

\subsection{Case 2: Minds of Youth, an Inclusive Blended Learning Community}

An immediate challenge for students learning from home is the absence of personal interactions with teachers and classmates. Video-based online classrooms and other expedient solutions for online learning are inadequate to facilitate social interactions among teenage learners. Therefore, it becomes difficult for students to have instant emotional support in the short run, or to obtain guidance for career path planning in the long term. Students reported having a hard time studying alone at home for an extended time. An online learning community provides opportunities for participating students to associate with peers and other learning partners, helping them maintain a high level of self-efficacy in an online learning scenario.

Minds of Youth is a small-scale inclusive learning community as well as a program for student social involvement designed and managed by THUHS. The Student Development Center of THUHS is the administrative entity of the MoY program. It aims to transform the learning experience by introducing an online community to the learners and by facilitating the participants to write and share. The primary goals of MoY are to encourage participating students to find internal study impetus, to adopt a more positive perspective for learning from home, and to find diverse ways to define the value of life, self, and others.

As part of the long-term strategy for THUHS students to gain real-life social experience, MoY also serves to expand students' scope of Chinese society by connecting them with contemporaries from less-developed areas in southwestern, southeastern, and central China.

The purpose of the Online Community is to provide both intellectual and mental support for younger students by inviting them to communicate with university students and faculties in a series of learning activities. 


\subsubsection{Participants}

The three 5-day learning camps admitted 166 students and 7 faculty members from Tsinghua University and THUHS. Students volunteered to participate in at least one of the three learning camps. Most students proposed to get enrolled for a second or even third time immediately after the closing ceremony of the previous camp, even though they knew the content and curriculum design would be very similar. The proportion of students from THUHS and partner schools are balanced (89 vs. 63) to ensure that applicants can form up into teams with diverse learning buddies. Students from elementary schools to universities are invited to provide a mixture of knowledge and experience and to boost peer learning (Table 5.2).

Organizers used an existing network with school administrators to find partner schools for MoY. Individual applications for enrollment were also accepted. As of June 30, 2020, 152 students had signed up for three camps. They came from 16 schools, including 8 in Hubei, 1 in Yunnan, 1 in Fujian, 1 in Anhui, 1 in Zhejiang, 1 in Sichuan, and THUHS in Beijing. The schools outside Beijing were in areas where the pandemic hit the most severely.

Fourteen sophomores from the School of Social Sciences at Tsinghua University volunteered to be mentors in MoY Camp III. They have backgrounds in sociology, international politics, and psychology (Table 5.3).

The MoY learning camps were designed by Weihang Cheng from THUHS Student Development Center and Yun Jin from THUHS Administration Center. The events in three MoY learning camps were prepared, coordinated, and supervised by Weihang Cheng. Three other teachers from THUHS and Tsinghua University participated as mentors.

Class teachers and parents of some participating students joined the WeChat group as observers without involvement in daily assignments or other learning tasks.

\subsubsection{Method}

The community held a series of 5-day online learning camps, inspiring participants with self-regulated learning, empowering them with learning methods and tools, as well as creating a supportive and inclusive learning environment for students from multiple grades. Participating students usually take one or more roles defined in the

Table 5.2 Numbers of Minds of Youth participants from different schools and grades

\begin{tabular}{l|l|l|l}
\hline & Tsinghua University & THU High School & Partner schools \\
\hline Grade 6 & - & - & 2 \\
\hline Grade $7-9$ & - & 70 & 61 \\
\hline Grade $10-12$ & 19 & - & - \\
\hline Undergraduate & 14 & - & - \\
\hline
\end{tabular}


Table 5.3 Numbers of Minds of Youth participants undertaking different roles

\begin{tabular}{l|c|l|l|l|l}
\hline & Learning buddies & Lecturers & Podcasters & Mentors & Organizing volunteers \\
\hline Grade 6 & 2 & - & 1 & 1 & - \\
\hline Grade $7-9$ & 131 & 12 & 11 & - & 10 \\
\hline Grade $10-12$ & 19 & - & - & - & 19 \\
\hline Undergraduate & 14 & - & - & 14 & - \\
\hline
\end{tabular}

community. They are all learning buddies by default and can additionally choose to be a lecturer, a podcaster, a mentor, or an organizing volunteer.

- A learning buddy participates in discussions and submits learning progress reports.

- A lecturer gives lectures on one of the learning topics.

- A podcaster provides one podcast on one of the learning topics.

- A mentor participates in discussions and responds to buddies' questions.

- An organizing volunteer coordinates events, designs slides and posters, or compiles deliverables.

Participating students and teachers use three platforms to coordinate learning activities:

- WeChat group chats, for morning lectures, evening podcasts, notifications, and free discussions.

- ShareDaka, a third-party mini-program run on WeChat for checking in daily learning tasks.

- Shimo Online Docs, for collaborative writing within co-create learning teams.

The core learning theme consists of four topics: a) flow, b) nonviolent communication, c) learned optimism, and d) a hero's journey. Lecturers work in a team of three to compile the content of one topic into slides and an explanation script with the help of mentors and organizing volunteers. At seven o'clock in the morning, lecturers post pictures and voice messages into the group chat and elaborate on that topic to their peers. On the same day, all learning buddies need to submit an essay on the topic to ShareDaka mini program. Afterwards, another group of students will collaborate and compose a podcast on the same subject matter after reviewing all the essays and post the voice messages into the group chat the next evening. At the end of each camp, all the essays are compiled into four digital books according to four topics by volunteers.

Meanwhile, all of the learning buddies are divided into eight to ten co-created learning teams. Team members are supposed to be from different provinces. Within each team, members take their own roles to enhance one another's sense of engagement. Generally speaking, one member will be in charge of managing the learning tasks every day, ensuring that everyone keeps on track with the intensive learning agenda. Another member will collect feedback and compose a line chart to visualize the teammates' daily mood swings. Aside from giving feedback on learning 
buddies' performance, mentors also initiate several discussions about any hesitation, confusion, or frustration incurred in the interactions or about other life issues.

\subsubsection{Data and Results}

The MoY team assessed the learning process with analytical data from administrative portals of the online learning tools. They also conducted interviews with stakeholders of the events, including students, parents, and class teachers.

The learning task completion rate reflects the involvement of students in the camps. A gap between students from THUHS and other schools indicates different baseline participation rate among students from different backgrounds (Table 5.4).

Students' self-reported expectations before the events were expressed via online application forms, and their comments on the learning experiences were collected through online interviews. Among all the purposes of participation mentioned, the top-ranked goals include "to be a better self" (37.8\%), "making new friends" (35.1\%), "enhancing writing skills" (32.4\%), and "supporting others" (18.9\%) (Fig. 5.1).

Post-event assessment contains several online interviews with students, parents, and their class teachers. The interviews include 5 Tencent Meeting video conferences, 10 one-on-one WeChat text or voice message talks, and 70 individual online questionnaires. In response to their claimed purposes, students reported having gained more than expected in MoY camps.

\subsubsection{Feedback from Participants}

\section{"Be a Better Self"}

Students found new perspectives to value themselves during learning activities. They began to view their life in a broader way in comparison to the original scope of schoolwork.

I feel lucky to be part of this, where I found a new and different way to live my life. Childish Lemon, Grade 7, Wuhan, Hubei

Devote into myself and think thoroughly through each topic, write down what's in my mind, leave behind judgment from others, and just be myself. - Peach, Grade 8, Beijing

Table 5.4 Learning task completion rates (The percentage indicates the total number of learning tasks finished out of all assigned tasks. The numbers in parenthesis indicate the number of students included in each camp)

\begin{tabular}{l|l|l|l}
\hline & Camp I & Camp II & Camp III \\
\hline THUHS & $97.06 \%(17)$ & $79.55 \%(22)$ & $87.04 \%(27)$ \\
\hline Schools outside Beijing & $70.83 \%(18)$ & $61.36 \%(22)$ & $91.66 \%(21)$ \\
\hline
\end{tabular}




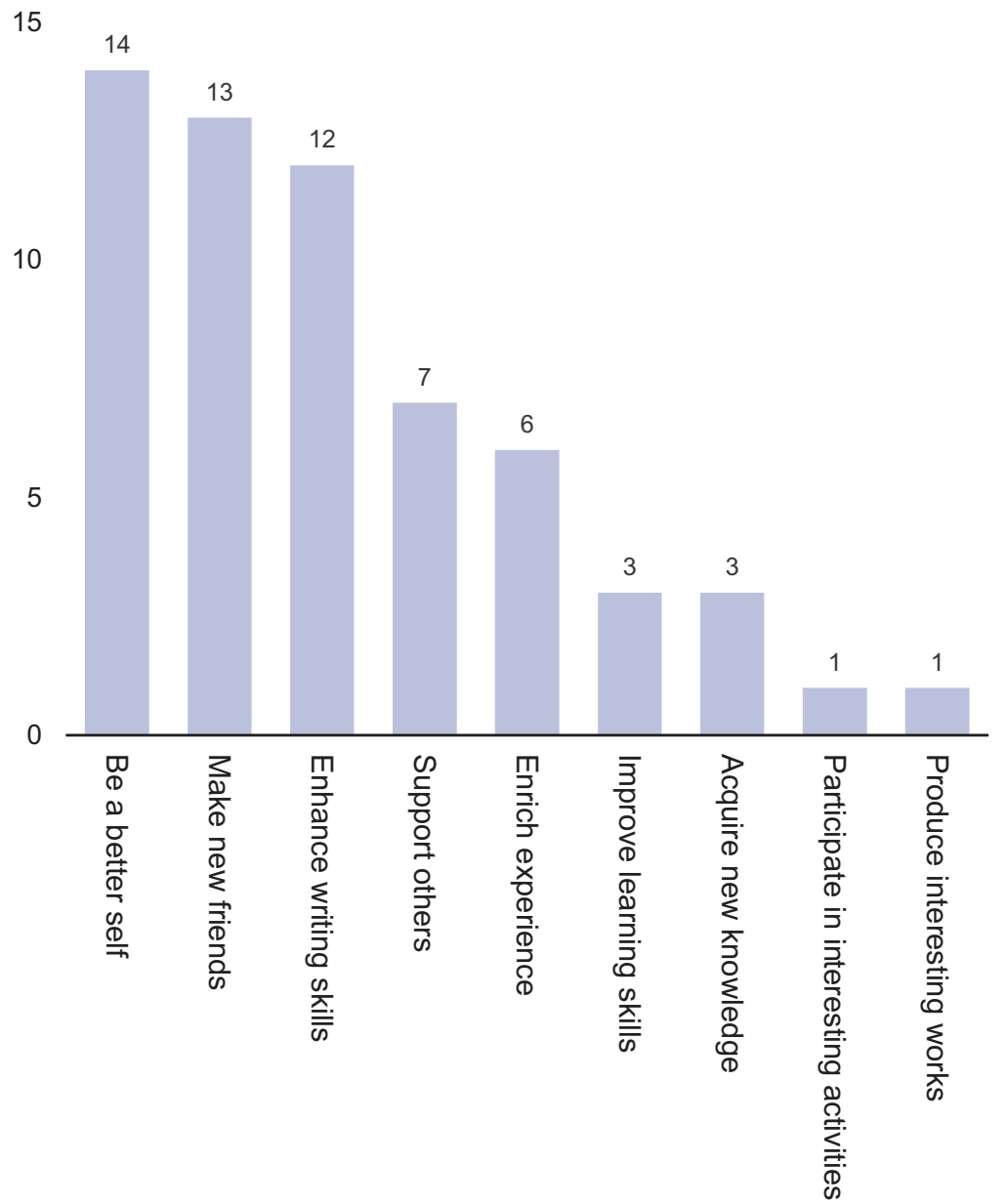

Fig. 5.1 Purposes of participating in MoY mentioned by students from 37 responses

I would like to participate again and challenge myself to be a podcaster. I missed the opportunity this time because of fear. I would definitely try something new next time. Bonnie, Grade 7, Wuhan, Hubei

\section{"Make New Friends"}

New friendships emerged between students from Beijing and other areas. They shared common interests and bridged the gaps of different life experiences and family backgrounds. They opened up to each other and built mutual trust to cherish their friendship. Many students extended their relationships well into their lives after the events. 
I made a lot of friends from Beijing, who share common values with me. They have similar hobbies as I do, and we share happiness and eagerness for beautiful things in life. The depth of friendship does not depend on how long people meet, but on how well their souls resonate. - Yuexixi, Grade 8, Jingzhou, Hubei

It truly was a special spring for me. When I listened to the MoY lectures and worked on the related assignments, I was still stuck in my everyday routine of courses and homework. Yet Minds of Youth brought surprises to my life. Within this community, I met with quite a few friends who shared similar interests with me. I'm sure it is one of the most enjoyable things in my life. I can get acquainted with people from far away, not only from around here. - Sextet, Grade 8, Wuhan, Hubei

This cohort of teenagers with distinctive backgrounds who share and fight for the same goal have brought light and color to my stereotyped life of dining, sleeping, writing, and watching. Now I begin to look out of the window, starting to wonder: the things that matter are not only studying and working hard, but connecting with all of you, despite that we are a thousand miles apart, without meeting in person. - Ian, Grade 7, Beijing

Not only have we college students shared our experiences with middle school students, but we've learned a lot from them about what contemporary teenagers are thinking and their perspectives of the society. It is thought-provoking to compare the buddies' ideas with what we used to think about the world, which was not far away back. - Ruoxing, sophomore, School of Social Sciences, Tsinghua University, Beijing

\section{"Enhance Writing Skills"}

The learning tasks involved a lot of writing. Students found it enjoyable and beneficial to write and share on a regular basis, even for a limited period of time. The fact that actual people were reading, talking about, and giving feedback to their works inspired participants' self-regulated learning in the most natural way. Hence the students became more and more self-driven with a certain purpose.

Each and every article melts in my heart; each and every podcast echoes in my head. Eaglet, Grade 7, Beijing

I have found myself making a lot of progress this week, in terms of both speech and writing. - Yuanzi, Grade 8, Jingzhou, Hubei

Dive into my own little world and retrieve my past quietly. I have found a small piece of undiscovered happiness from my long-sealed past. How long has it been since the last time you wrote down anything authentic from your heart? Forget about those tricks to get a high score in writing, and forget about the second-hand stories told by others. - Yisheng, Grade 8, Jingzhou, Hubei

\subsubsection{Feedback from Parents and Teachers}

Two conflicting points of view exist among parents about such unconventional learning activities. On the one hand, parents struggle to find opportunities to build closer relationships with children whose time is occupied with schoolwork. On the other hand, parents consider that having extra-curriculum learning activities will waste too much time, even though the MoY tasks are designed to optimize parentchild relationship. 
1. Case A [Positive]: A sixth grader from Chengdu, Sichuan, volunteered to be a podcaster. She used to be regarded as a typical rebellious adolescent since she always quarreled with her parents. During her time in MoY, she became more active and better engaged in learning. Her parents witnessed how she was taking responsibility when working with her peers to prepare for the podcast, not the trouble-making girl anymore. Afterward, both of her parents dropped prejudice and decided to give their daughter more freedom. And the family reported to enjoy a more harmonious parent-child relationship.

2. Case B [Negative]: A father from Jingzhou, Hubei, and a mother from Xiantao, Hubei, found it challenging to balance the MoY tasks and subject learning. They decided that the students were better off not spending time on these online activities in order to allocate more effort to subject learning. Although the two are rare cases in the camp, they reflect a widely spread misunderstanding that the learning environment and social interactions are isolated and irrelevant to students' performance.

To most parents' surprise, MoY has been proven to improve children's overall academic performance by nurturing a positive learning atmosphere as well as a healthy psychological and mental state. The following shows some observations of the campers by their parents:

It's not that we want to fight with our child, but that we are not able to find a pivot point to open his world. In MoY, sense of fulfillment and joy replaces his purposelessness by means of free writing. We feel grateful for this event and hope it can last forever! Thanks to MoY, my son and his fellow students in Hubei have been illumined to find their own directions. Parents of an 8-grader, Shiyan, Hubei

Being part of MoY truly brought some changes to my kid. First, he began to love writing, which used to be his biggest problem at school. In this event, he read others' work and found a lot of inspirations. He talked about writing to his new friends, filled with purposes and interests. He delightfully joined the daily online meetings punctually, and carefully chose the words for each sentence. I believe that is the magic of open topic writing. In addition, the enthusiasm from the MoY buddies enhanced my son's confidence and interest in learning. I truly appreciate the teachers and students who made this event possible. - Parents of a 6-grader, Wuhan, Hubei

Generally speaking, the transform in learning attitudes will help improve students' performance in schoolwork. Class teachers who are in favor of students participating in MoY also reported that students demonstrated a more positive attitude toward learning after the camp.

I notice that Zhang has grown to be more and more self-disciplined. She had to study at home on her own because both of her parents had been back to work since the beginning of March. To my surprise, she became even more self-regulated while she had easy access to smart phones and computers. I did witness the improvement of Zhang's performance in online courses and exams. And I had no doubt that she had learned a lot from MoY when she shared with me her plan of introducing a similar program to our class in order to involve more classmates in. What a smart girl with critical thinking and the ability to transfer! I will be more than grateful to see this girl's promising future. - Comments from Zhang's class teacher in THUHS, Beijing 


\subsubsection{Future Plan}

Expanding the Sphere of Influence in THUHS.

Positive results from the three learning camps of MoY boosted the confidence of administrations of THUHS. The Career Planning Office of the Student Development Center is working with the founding team of MoY to make plans for more learning camps in the following summer vacation. More students from Grade 7 to Grade 11 will be encouraged to sign up.

Optimizing the Format and Content.

Taking advantage of combining the MoY camp with social practice, THUHS will produce more possibilities for students. Merging the online phase and the offline phase together, the school's summer or winter study tour will create a more comprehensive learning experience. For instance, in the preparation stage, the students are supposed to participate in the online camp with learning buddies of the same age from one or two schools in the travel destination. Once the travel starts, students from both THUHS and the cooperative school will meet with each other in the on-site activities.

It has also been suggested that more knowledge of developmental psychology should be introduced to the program. Therefore, the MoY camp can be transferred to be an orientation camp for Grade 7 and Grade 10, which are respectively the starting grades of junior high school and senior high school. Moreover, an additional part of parent-child communication may enable the program to be more family-friendly.

Applying the Pedagogy to Semester Courses.

The event has attracted several teachers from THUHS to be observers in the past three camps. They have found it so impressive and positive that they are considering applying the strategy to their semester courses. In fact, one of the teachers is already planning another online summer camp focused on science of learning following the format of MoY.

\subsection{Discussion of this Chapter}

In the past 5 months, efforts to maintain a high level of engagement with students have yielded positive results. Online events are overall more capable of maximizing outreach and influence. Feedback collected from informal ways such as messaging with organizers reflects that the outcomes of most events have exceeded audiences' expectations. In the meantime, some obstacles are identified for further improvement, and some unexpected values from the events are evaluated and discussed. 


\section{A Better Experience for More People.}

Feedback from science teachers in elementary and secondary level schools have confirmed that ITCOF talks are useful and practical. They left comments on virtual tours to Tsinghua iCenter, saying that the experience was impressive. Students regarded it as a once-in-a-lifetime experience. Teachers who visited iCenter in person before described the online virtual tour as more efficient since "the contents are well-orchestrated and presented by the person most suitable for the job, thus everyone owns the best vista point."

\section{Online Learning Communities Help Students Keep Motivated.}

A critical issue for learning from home is motivation management for both completing daily learning tasks and preparing for future career paths. It is widely reported by class teachers that students often experience a loss of mindfulness learning from home. Key reasons include the drastic change in the learning environment and the absence of peer learners. Homes are full of distractions, such as food and playful items. Video-conference-style online classes are widely adopted by schools in China during the pandemic. Interactions with peer learners will possibly drop to a minimal level when students engage with the class only through a screen with a camera, which is more often than not left switched off by students. An online learning community that requires students to work in teams and complete group tasks has proven to be accepted and effective among students and their guardians.

In MoY learning camps, most students gained learning motivation and better relationships with guardians after the 5-day experience. It turned out that the only adverse factor was a few guardians' lack of understanding about the purpose of such learning communities.

A distinctive feature of learning tasks in MoY is that they require students to use diverse skillsets and mindsets. Students who understand this are more willing to participate multiple times to try out and practice with different roles. Generally speaking, students who fall behind academically hardly enjoy the sense of presence in the fierce competition at school. By contrast, MoY provides a huge stage for them to unfold their hidden skills such as poster designing, eloquence, etc. In a word, MoY is an inclusive learning community where peers celebrate all kinds of talents and teenagers build up self-efficacy.

Many other cases provide evidence that the online learning community is an effective way to keep students motivated. However, whether the effects on selfefficacy building and motivation boosting will persist after the camp is left for further investigation.

Mixed-Grade Learning on a Larger Scale.

ITCOF and ALL create large open platforms for learners, teachers, and other stakeholders to exchange ideas and to communicate. Students report the lectures given by professors have transformed their understanding of learning and research in a university. They set up an internal goal of realizing a better self and earning the 
opportunities to study with peers. It goes far beyond the external goals they initially held of scoring higher in the next exam to satisfy their parents and teachers.

The discussions with undergraduates in MoY have deeply impressed the middle school students. These young people started to make connections between what they are currently learning and what will be used in the future. They can also raise questions for "college student mentors" about what careers they are pursuing after graduation. Such a question is usually rare among high school students either because they do not have much time to think about it or because they simply do not have anyone to turn to when the question arises.

Quality of the Content.

As for online talks and courses, the larger audience brings about more uncertainties in the preparation stage due to diverse backgrounds of listeners. It requires the presenters to think through the content more thoroughly in advance and predict what questions might be most appropriate and effective. Online platforms provide instant feedback to speakers. Compared with traditional ways of questionnaire or interview, the real-time comments from audiences are more accessible for speakers to review and reflect on, in order to improve and iterate the speech content.

Moreover, the availability and accessibility of online content increased peer learning among experts. A distinguished guest to ITCOF viewed all the talks before him. He used what he learned from both the speakers and the audiences to tailor his presentation and responded to some key issues addressed. As a result, his talk was viewed by over 10,000 unique users, ranking third among all 18 talks.

From Live Show to Short Video.

Switching from classroom learning to online learning leads to an increase of electronic device usage among students. Since last year, short videos have consumed more time of Internet users than ever. A video that goes viral can easily earn millions of views within days. Live shows that take an equivalent time as traditional classes are merely a preliminary solution. New formats for online learning are still to be explored. Nonetheless, whether online learning can be a more substantial part of the blended learning format is yet to be proven.

\section{References}

Luckin, R., \& Weatherby, K. (2012). Online learning communities in context. International Journal of Web Based Communities, 8(4), 440-454.

Sampson, J., Boud, D., Cohen, R., \& Gaynor, F. (2001). Designing peer learning. HERDSA Annual International Conference.

Zeneli, M., Tymms, P., \& Bolden, D. (2018). Interdependent cross-age peer tutoring in mathematics. International Journal of Psychology and Educational Studies, 5(3), 33-50. 
Woody Wang is the Director of Innovation Education Pillar at iCenter, Tsinghua University. His major is industrial engineering, which gave him the insight in systematically managing college students' innovation and entrepreneurship projects. He serves as the Secretary General of Maker Education Base Alliance, which has 178 members of universities, colleges, and enterprises in education industry around the country. Woody has 7 years of rich experience in entrepreneurship education, collaborative learning, VR/AR and simulation, industrial system design, humanmachine interaction design, etc. He is one of the instructors for TEDxTHU and THU Makerspace Student Club. His achievement has been published on domestic and international journals and conferences.

Weihang Cheng is a political science teacher of Tsinghua University High School (THUHS). As a former student development counselor, she was responsible for designing and coordinating student activities in THUHS. Before she was awarded an MA in Education, Policy and Society by King's College London, Weihang had already gained rich teaching experience in project-based learning and experiential learning. After receiving her Bachelor of Law in Sociology from Tsinghua University, she joined Teach For China, a non-governmental organization, and dedicated herself to a 2-year volunteer teaching project at two schools in rural southwestern China.

Yun Jin is a teacher of English at Tsinghua University High School (THUHS). She hosts multiple selective courses about learning sciences. She received her BA degree at Beijing Normal University. Her research interests include how to create an immersive learning experience for students with specially orchestrated learning activities and a refined reward system.

Ivy Guo is both a researcher in learning sciences and an entrepreneur in education technology. Ivy received her MA in Learning, Design and Technology from Stanford University and her BS in Psychology with honors from the University of Illinois Urbana-Champaign. Ivy translated the book, The ABCs of How We Learn, and introduced the concept of Scientific Learning into China. She collaborates with top high schools and universities to make an impact among students, teachers, and parents. She is also a founding team member of Tsinghua University Lab for Lifelong Learning.

Open Access This chapter is licensed under the terms of the Creative Commons Attribution 4.0 International License (http://creativecommons.org/licenses/by/4.0/), which permits use, sharing, adaptation, distribution and reproduction in any medium or format, as long as you give appropriate credit to the original author(s) and the source, provide a link to the Creative Commons license and indicate if changes were made.

The images or other third party material in this chapter are included in the chapter's Creative Commons license, unless indicated otherwise in a credit line to the material. If material is not included in the chapter's Creative Commons license and your intended use is not permitted by statutory regulation or exceeds the permitted use, you will need to obtain permission directly from the copyright holder. 